\title{
ENVIRONMENTAL ADVANTAGES OF TREATMENT PLANTS GENERATING BIOMETHANE FROM FOOD WASTE
}

\author{
MARCO SCHIAVON ${ }^{1}$, ELENA CRISTINA RADA ${ }^{1,2,3}$, MARCO RAGAZZI $^{1}$, \\ LUCIAN-IONEL CIOCA ${ }^{3} \&$ VINCENZO TORRETTA ${ }^{2}$ \\ ${ }^{1}$ Department of Civil Environmental and Mechanical Engineering, University of Trento, Italy \\ ${ }^{2}$ Department of Theoretical and Applied Sciences, University of Insubria, Varese, Italy \\ ${ }^{3}$ Department of Industrial Engineering and Management, Lucian Blaga University of Sibiu, Romania
}

\begin{abstract}
Biomethane is an emerging sector in Europe as evolution of the conventional approach of co-generation of biogas based on an engine. The countries in Europe are facing this option according to different temporal dynamics. From the technical point of view, a common need is to have available tools and calculations suitable to analyse the environmental advantages of this approach. The present article compares the emissions from three options for biogas valorisation: combined heat and power generation for electric energy supply to an electricity distribution network, biomethane production through pressurised water scrubbing and biomethane production through chemical absorption. In the last two cases, biomethane is considered for usage by public natural-gas buses. Data and parameters used for the balances are taken from international databases. Results demonstrate the advantages of biomethane. Keywords: anaerobic digestion, biogas, biomethane, composting, emissions.
\end{abstract}

\section{INTRODUCTION}

Biomethane is a novelty in many European countries. In some cases, the novelty is absolute (e.g. Romania). In other cases, the regulation of the sector is close to be defined (e.g. Italy). The reasons of this inhomogeneity in the European countries depends on the different approaches in organising food waste collection and in supporting the sector of methane from discarded biogas. In particular, in Romania source separated collection of organic fraction of municipal solid waste (OFMSW) is going to be organised as first case in one region. This is the only approach that guarantees a biogas of high quality, compulsory for an efficient extraction of methane from biogas. Thus, Romania does not discuss yet about biomethane because a previous step of the pathway is still missing. In Italy, the delay is mainly related to the upgrading of the regulation of the sector. One of the problems is the calculation of the equivalence of the incentive given for a production of electricity from biogas, with the incentive to be given when no local electrical generation is made because of the conversion of biogas into biomethane. Another problem is related to the authorisation of a biomethane plant when a conventional engine based plant is already authorised.

In spite of the above-mentioned problems, the extraction of methane from biogas opens to new perspectives for its exploitation. As previously written, the preferred approach refers to a biomethane production based on biogas from source separated food waste collection as biogas from landfills is still considered difficult to treat: indeed, biomethane must guarantee high standards of composition that can be hard to reach if the starting biogas is reach in micropollutants. In this scenario, a question raising also in countries where the biomethane option is already performed is: which are the differences of emissions to the atmosphere from conventional solutions when a biomethane option is chosen? The present paper wants to give a contribution to this discussion that concerns also the conversion of composting plants into anaerobic digestion plants.

Typically, a composting plant in European Union is composed as follows: 
- an accumulation chamber, which collects the incoming source separated OFMSW and where the latter is weighed, grinded, sieved and mixed with green waste;

- an aerobic stabilisation stage, where the refined waste mixture undergoes aerobic biodegradation for about 30 days, after which the organic waste can be considered as stabilised;

- a maturation stage, where the stabilised waste stays for about 60 days;

- a storage area, where the high-quality compost is packed and prepared for the market.

Usually, the discharge of OFMSW and all the operations carried out until the end of the aerobic stabilisation phase are supposed to occur in a close indoor environment, where the air is continuously blown and sent to the air treatment line, for the removal of volatile organic compounds (VOCs), ammonia, hydrogen sulphide and odours. Conversely, the maturation stage and the compost warehousing usually occur in an open hangar. In such conditions, emissions of particulate matter (PM) and odorants from the open compartments into the atmosphere are unavoidable and may cause odour nuisance to residents possibly settled nearby.

When moving to an anaerobic digestion stage followed by post-composting, in addition to obvious advantages in terms of biogas production, potential benefits are expected also from the point of view of emissions into the atmosphere. Indeed, with this new configuration, the phase that most contributes to the release of odorants is now managed in a closed anaerobic reactor. Its solid output (the digestate) is a semi-stabilised material, whose respirometric index is relatively low. In the Italian respirometric scenario, it is typically close to (or even below) $1000 \mathrm{mg}_{\mathrm{O} 2} \mathrm{~kg}^{-1} \mathrm{~h}^{-1}$ of volatile solids, which is the lower limit to define biomass as stable according to the Italian Standard UNI 11184:2006 by a dynamic respirometric method. The gaseous output is biogas, which is subsequently exploited for energy production and not directly released into the atmosphere as exhausted gas, differently from the case of direct composting. Compared to composting, the advantages of applying aerobic biodegradation to an almost stable waste consist in the reduced release of odorants in the subsequent phases, the lower amount of air needed for the aerobic phase and the consequent lower odorant load in the air treatment line. However, other emissions are produced, due to the local combustion of biogas or to methane $\left(\mathrm{CH}_{4}\right)$ leaks.

Different options are available for the exploitation of the produced biogas. In the light of these considerations, this paper aims at comparing the emission balance from three different options for biogas valorisation: combined heat and power (CHP) generation for electric energy supply to an electricity distribution network, biomethane production through pressurised water scrubbing and biomethane production through chemical absorption. In the last two cases, biomethane will be considered for usage by public natural-gas buses.

\section{ANAEROBIC DIGESTION AND POST-COMPOSTING}

\subsection{Definition of the case study and the related scenarios}

Specifically, the case study is based on the conversion of the typical configuration of a composting process into:

- a semi-dry anaerobic digester, operated under thermophilic conditions $\left(55^{\circ} \mathrm{C}\right)$, with a biogas productivity set to $142 \mathrm{Nm}^{3}$ tofMSw $^{-1}$, chosen on the basis of a reference 
semi-dry anaerobic digester (typical values for this technology are in the range $100-150 \mathrm{Nm}^{3}$ tofMSw $^{-1}$ );

- a second biological step, where the digestate is mixed with green waste (accounting for $20-5 \%$ of the total amount of waste) and undergoes aerobic biostabilisation;

- a maturation stage, with subsequent sieving and refining;

- a storage compartment, where high-quality compost is packed.

To further reduce the release of PM and odorants, the maturation and storage compartments are assumed to occur in closed hangars. In terms of space, this configuration does not require more surface than the traditional composting process with the same amount of treated waste, due to the lower duration of the maturation stage and to the consequent lower space required for biostabilisation and maturation, which compensates the space necessary for the anaerobic digester and the biogas exploitation units.

Concerning the modalities of exploitation of the biogas generated by the anaerobic digestion stage, three scenarios are here considered (Fig. 1):

- Case 1. The produced biogas is sent to a desulphurisation unit and then to a CHP generator. Electric energy is partly used to cover the electric consumption of the facility and is partly sent to the electricity distribution network at medium voltage; the heat recovered from the cooling water, from the oil circuit and from the exhaust gas is used to heat the digester (Fig. 1(a)).

- Case $2.12 \%$ of the produced biogas is partly burnt in a boiler, to generate the heat to keep the digester under thermophile conditions, while the remaining biogas $(88 \%)$ is sent to a biogas upgrading system consisting in a pressurized water scrubber, with the purpose of producing biomethane to feed public buses (Fig. 1(b));

- Case 3. This case is analogous to Case 2, with the only difference that the biogas upgrading process is carried out with chemical absorption; the boiler provides heat only to the digester; the necessary heat to regenerate the chemical solvent is supplied by a dedicated heater (Fig. 1(c)).

- Both pressurized water scrubbing and chemical absorption are consolidated technologies and have been widely employed for biogas upgrading [1]-[5]. Differently from chemical absorption, pressurized water scrubbing does not require heat, since water is regenerated by an air current at ambient temperature.

\subsection{Considered pollutants}

The assessment of emissions from the three scenarios considers both global and local air pollutants. The here considered global pollutants are $\mathrm{CO}_{2}$ and $\mathrm{CH}_{4}$, which are direct responsible for global warming. The emissions of $\mathrm{CO}_{2}$ deriving from energy conversion of natural non-fossil materials are balanced by the $\mathrm{CO}_{2}$ required for their production and directly absorbed from the atmosphere. For this reason, the $\mathrm{CO}_{2}$ balance is considered as neutral in all three cases. On the contrary, $\mathrm{CH}_{4}$ emissions are not compensated with absorption by natural organic substances. In addition, the global warming potential of $\mathrm{CH}_{4}$ is equal to 25 on a reference period of 100 years. $\mathrm{CH}_{4}$ is released during its usage and through leaks from the upgrading process. The latter are assumed as equal to $1 \%$ and $0.1 \%$ when pressurized water scrubbing or chemical absorption are adopted, respectively.

Among the local air pollutants emitted from the biogas exploitation line, nitrogen oxides $\left(\mathrm{NO}_{\mathrm{x}}\right)$, sulphur dioxide $\left(\mathrm{SO}_{2}\right), \mathrm{PM}$, non-methane VOCs (NMVOCs) and carbon monoxide (CO) are considered. $\mathrm{NO}_{\mathrm{x}}$ and $\mathrm{SO}_{2}$ are also precursors of secondary $\mathrm{PM}$, whose formation is 


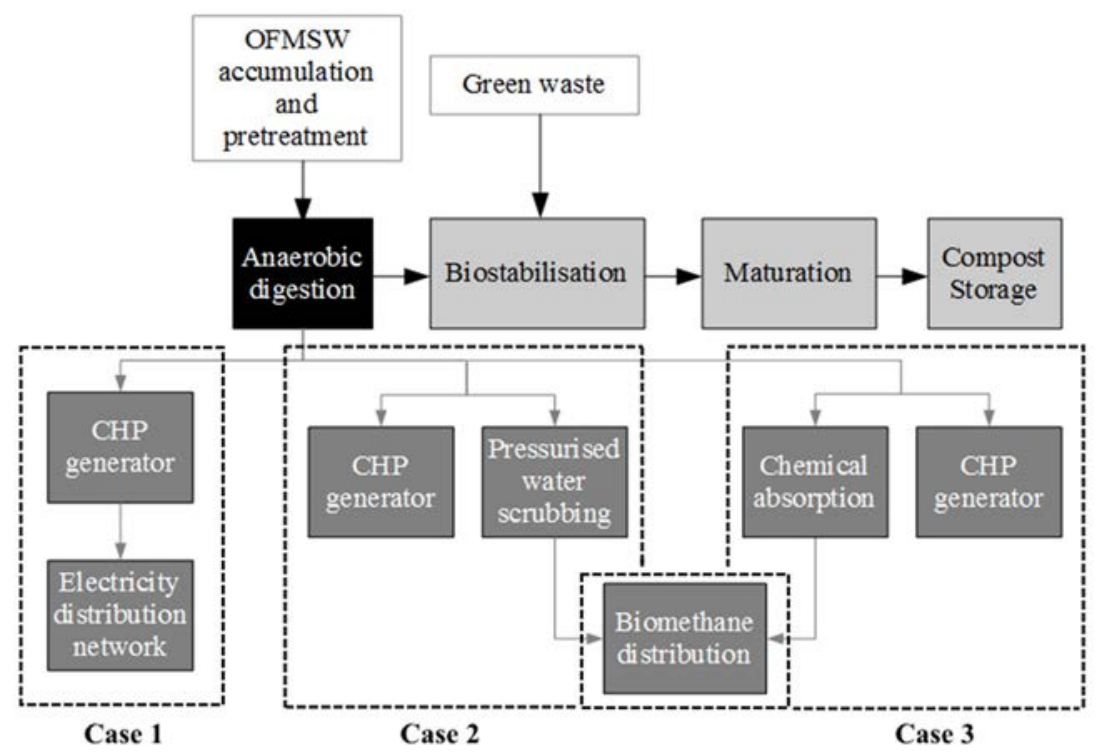

Figure 1: Flow diagrams of the configurations assumed in the three compared cases.

estimated through application of the hypotheses formulated by [6]. In view of the comparison between the three presented cases, the emissions from the air treatment line of the three configurations are considered as equal in all cases, as an adequate design allows it. Therefore, these emissions will not be taken into account in the emission balances.

\subsubsection{Case 1}

Emission factors for non-methane VOCs and $\mathrm{SO}_{2}$ and emitted by the CHP generator were retrieved from the CORINAIR methodology developed by the European Environment Agency [7]. Concerning PM, $\mathrm{CO}$ and $\mathrm{NO}_{\mathrm{x}}$, emission factors were re-calculated on the basis of the corresponding emission limits set by the European Union [8]. $\mathrm{The}^{\mathrm{CH}_{4}}$ emission factor was retrieved by the Danish emission inventory for stationary combustion plants [9]. The adopted emission factors are summarised in Table 1 and are referred to the unit energy of input $\mathrm{CH}_{4}$. If considering the biogas productivity of $142 \mathrm{Nm}^{3}$ toFMSw $^{-1}, \mathrm{a} \mathrm{CH}_{4}$ content of $60 \%$ $\mathrm{v} / \mathrm{v}, \mathrm{a} \mathrm{CH}_{4}$ lower heating value of $35.28 \mathrm{MJ} \mathrm{Nm}^{-3}$ and assuming that the CHP generator works for $8,000 \mathrm{~h} \mathrm{y}^{-1}$, the specific annual input energy for the CHP generator is $2.75 \mathrm{GJ}_{\mathrm{OFMSW}^{-1}} \mathrm{y}^{-}$ 1 . The efficiencies of the CHP generator in terms of electric and thermal energy conversion are assumed as equal to $38 \%$ and $40 \%$, respectively. The resulting electric and thermal energy productions are $1.05 \mathrm{GJ}_{\text {OFMSW }}{ }^{-1} \mathrm{y}^{-1}$ and $1.10 \mathrm{GJ}_{\text {OFMSW }}{ }^{-1} \mathrm{y}^{-1}$, respectively. In addition, it is assumed that $10 \%$ of the produced electric energy $\left(0.11 \mathrm{GJ} \mathrm{toFMSW}^{-1} \mathrm{y}^{-1}\right)$ and $25 \%$ of the produced thermal energy $\left(0.28 \mathrm{GJ}_{\mathrm{OFMSW}}{ }^{-1} \mathrm{y}^{-1}\right)$ are used in the facility to cover the energy consumption for the anaerobic digester and the aeration of the biostabilisation process. 
Table 1: Emission factors (expressed as $\mathrm{g} \mathrm{GJ}^{-1}$ of input fuel) adopted for the production of energy from the average mix of energy sources in Italy and for CHP generators [7]-[10].

\begin{tabular}{ccc}
\hline Pollutant & $\begin{array}{c}\text { Average national mix of } \\
\text { conventional sources }\end{array}$ & CHP generator \\
\hline $\mathrm{CO}$ & 16.5 & 28 \\
$\mathrm{NO}_{x}$ & 35 & 21 \\
$\mathrm{CO}_{2}$ & 65,000 & 0 \\
$\mathrm{NMVOCs}$ & 2.1 & 45 \\
$\mathrm{PM}$ & 0.8 & 2 \\
$\mathrm{SO}_{2}$ & 20.7 & 0.5 \\
$\mathrm{CH}_{4}$ & 3 & 434 \\
\hline
\end{tabular}

Therefore, the excess electric energy production that is sent to the electricity distribution network is $0.94 \mathrm{GJ} \mathrm{t}_{\mathrm{OFMSW}}{ }^{-1} \mathrm{y}^{-1}$. The specific annual emissions for electric energy production can be estimated by multiplying this value by the emission factor of each pollutant.

Since no biomethane production for public transportation is considered in this scenario, this missing positive effect must be compensated with emissions from an average fleet of urban buses covering the same distance per ton of input OFMSW, whose calculation will be discussed in Section 2.2.2. Emission factors concerning the average Italian bus fleet were estimated by the Italian Institute for Environmental Protection and Research (ISPRA), based on the COPERT 4 methodology [7], and are reported in Table 2.

\subsubsection{Case 2}

In the hypothesis that all the biomethane produced is used by the local fleet of public buses, emission factors from buses fed with natural gas were retrieved from the COPERT 4 emission model (Table 2), to ensure consistency with the emission factors concerning the average Italian fleet of urban buses [11]. Internal electric and thermal energy consumptions are assumed to be the same as Case 1 and are covered by the CHP generator, which uses the strictly necessary biogas flow to this purpose. The minimum specific amount of biogas for self-sustainment of the facility results as equal to $35.5 \mathrm{Nm} 3$ tOFMSW-1. Therefore, the biogas sent to upgrading is $106.5 \mathrm{Nm} 3$ tOFMSW-1. Considered the $\mathrm{CH} 4$ loss of $1 \%$ for pressurised water scrubbing and a $60 \%$ content of $\mathrm{CH} 4$ in biogas, the specific biomethane

Table 2: Emission factors (expressed as $\mathrm{g} \mathrm{km}^{-1}$ ) adopted for the estimation of the emissions from the average Italian fleet of urban public buses and from urban buses fed with natural gas (NG), and average fuel consumptions [11].

\begin{tabular}{ccc}
\hline Pollutant & $\begin{array}{c}\text { Average national fleet } \\
\text { of public buses }\end{array}$ & NG-fed urban buses \\
\hline $\mathrm{CO}$ & 1.57 & 28 \\
$\mathrm{NO}_{\mathrm{x}}$ & 6.4 & 21 \\
$\mathrm{CO}_{2}$ & 699 & 0 \\
$\mathrm{NMVOC}_{\mathrm{PM}}$ & 0.26 & 45 \\
$\mathrm{SO}$ & 0.17 & 2 \\
$\mathrm{CH}_{4}$ & 0.003 & 0.5 \\
Fuel consumption $\left[\mathrm{g} \mathrm{km}^{-1}\right]$ & 0.098 & 434 \\
\hline
\end{tabular}


production is $63.3 \mathrm{Nm} 3$ tOFMSW-1. Such value, coupled with the $\mathrm{CH} 4$ densitiy of $656 \mathrm{~g}$ $\mathrm{m}-3$ and with the biomethane consumption estimated by COPERT $4(455 \mathrm{~g} \mathrm{~km}-1)$, allows for a specific distance travelled of $91.2 \mathrm{~km} \mathrm{toFMSW}^{-1}$. To compare the three scenarios, the same distance travelled is assumed in Case 1 and Case 3.

The emission balance of Case 2 must account for the missing production of excess electric energy by the CHP generator. This missing contribution is assumed to be replaced by a corresponding amount of electric energy generated by conventional sources. Emission factors for $\mathrm{CO} 2$ and $\mathrm{CH} 4$ concerning the mix of sources used in Italy for electric energy production in 2013 were adopted in this case [10] and are expressed in terms of unit energy of the input fuel (Table 1). The conversion efficiency to electric and thermal energies are conveniently assumed as $38 \%$ and $40 \%$, as in the case of the CHP generator.

In addition, biogas upgrading via pressurised water scrubbing requires an electrical energy consumption estimated as $0.3 \mathrm{kWh} \mathrm{Nm}^{-3}$ of treated biogas. This additional energy is assumed to be provided by conventional energy sources.

\subsubsection{Case 3}

Concerning the emissions that originate from the missing production of excess electric energy by the CHP generator, the same emissions as of Case 2 are expected. Differently from Case 2, a lower CH4 loss $(0.1 \%)$ is expected when upgrading biogas with chemical absorption. Therefore, the biomethane production is slightly higher and results as $63.8 \mathrm{Nm}^{3}$ tofMSw $^{-1}$. The specific distance travelled would result in $92.0 \mathrm{~km} \mathrm{toFMSw}^{-1}$. However, to compare the three scenarios, the same distance as of Case 2 is considered, and the excess biomethane is assumed to be stored in a gas reservoir.

Biogas upgrading through chemical absorption requires both electric energy and thermal energy to regenerate the solvent. The estimated energy consumption for chemical adsorption are 0.1 and $0.5 \mathrm{kWh} \mathrm{Nm}^{-3}$ for electric and thermal energy, respectively. In analogy with Case 2 , this additional amount of energy is assumed to be provided by conventional sources.

\section{RESULTS AND DISCUSSION}

The emissive contributions of electric energy production by the CHP generator (only for Case 1), public transportation, electric energy compensation from conventional sources (Case 2 and Case 3), energy consumption for biogas upgrading (Case 2 and Case 3 ) and $\mathrm{CH}_{4}$ losses from biogas upgrading (Case 2 and Case 3 ) are summarised in Fig. 2. $\mathrm{CH}_{4}$ emissions were more conveniently converted to equivalent $\mathrm{CO}_{2}$ emissions $\left(\mathrm{CO}_{2 \mathrm{eq}}\right)$, since they produce the same kind of global impact. Emissions refers to the unit mass of input OFMSW.

As expected, the contribution of public transportation to the emissions of the considered pollutants is higher when urban buses are not fed with the biomethane producible by upgrading the biogas formed in the anaerobic digestion stage (Case 1). The only exception concerns NMVOCs, whose emission factor is higher in NG-fed urban buses, as reported in Table 2. With regards to Case 2 and Case 3, the generation of local air pollutants is higher when chemical absorption is chosen as the biogas upgrading. On the other hand, chemical absorption implies lower emissions of global pollutants $\left(\mathrm{CO}_{2 \mathrm{eq}}\right)$, mainly due to lower $\mathrm{CH}_{4}$ losses. Therefore, when choosing between pressurised water scrubbing and chemical absorption as the biogas upgrading option, one should consider the potential environmental impacts involved. The final choice could be made on the location of the biogas upgrading plant. Indeed, in case resident population is settled near the plant or if the emissive context of the area is already critical due to the presence of several other emission sources, the local impacts induced by the biogas upgrading option should be as low as possible. Thus, pressurised water scrubbing would be the preferred choice from the point of view of human 

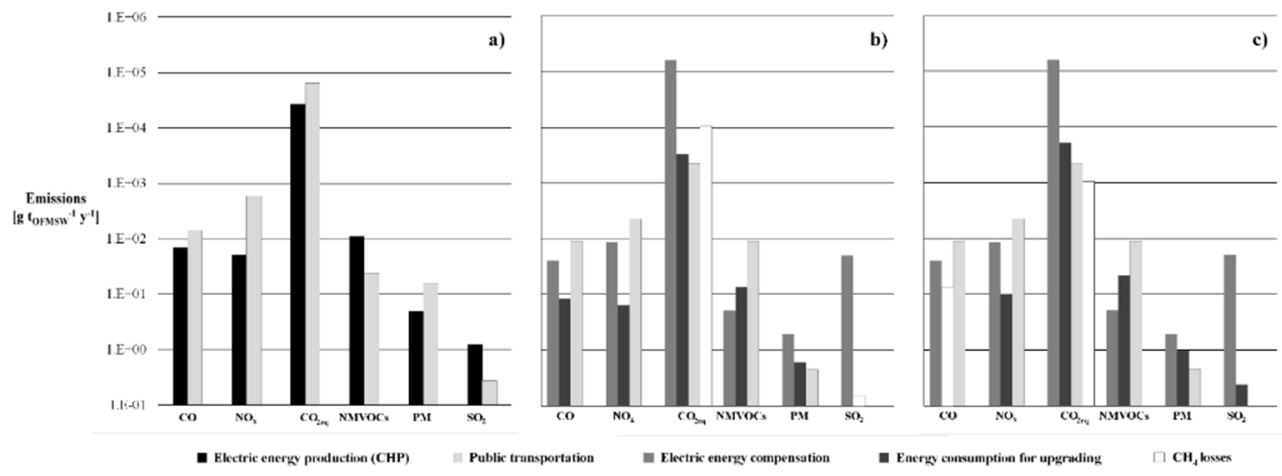

Figure 2: Contribution of each emissive item to the emissions of the considered pollutants from (a) Case 1, (b) Case 2 and (c) Case 3.

health. In comparison with chemical absorption, pressurised water scrubbing also requires lower energy to operate, but this economic convenience is counterbalanced by the higher $\mathrm{CH}_{4}$ losses and $\mathrm{CO}_{2 \text { eq }}$ generation.

The total emissions of the reference pollutants with respect to the three considered scenarios are presented in Fig. 3. In general, Case 1 generates a higher amount of local pollutants than Case 2 and Case 3, with the only exception of $\mathrm{SO}_{2}$, whose emission is three times lower. From the point of view of global pollutants, $\mathrm{CO}_{2 \mathrm{eq}}$ emissions from Case 2 and Case 3 almost double in comparison to Case 1, although their total $\mathrm{CH}_{4}$ emissions are almost half the $\mathrm{CH}_{4}$ emissions from Case 1. The main reason for these higher results in $\mathrm{CO}_{2 \mathrm{eq}}$ contribution is related to the higher $\mathrm{CO}_{2}$ emissions due to the missing production of electric energy for distribution in the electricity network, which must be compensated by electric energy produced by conventional sources.

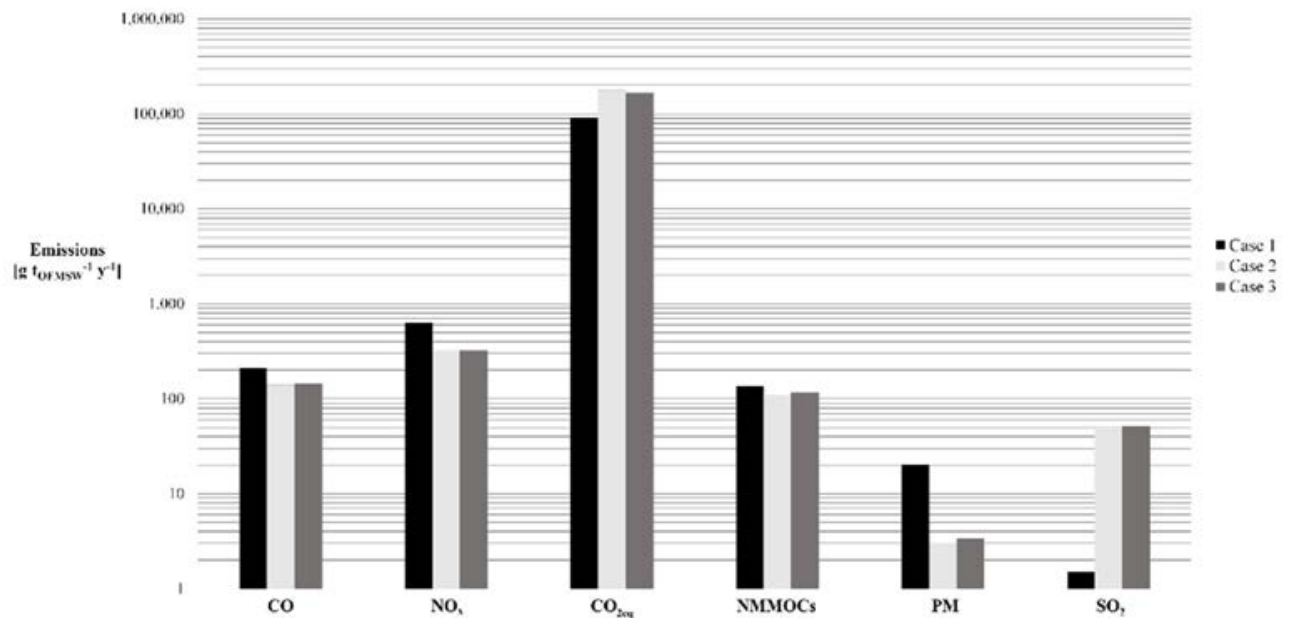

Figure 3: Total emissions generated in the three considered scenarios. 


\section{CONCLUSIONS}

Anaerobic digestion of OFMSW, followed by post-composting of the digestate, has the undoubted advantage of generating an energy source as biogas with the same or lower space requirements as the traditional composting process. However, different options to exploit the produced biogas entail different results in the emissive balance. Compared to biogas upgrading and use of biomethane in the public transportation system, the production of electricity through biogas combustion in a CHP generator generates a lower amount of $\mathrm{CO} 2 \mathrm{eq}$ but higher amounts of local air pollutants. Between the two studied options for biogas upgrading, pressurized water scrubbing would lead to slightly lower local impacts. In conclusion, the preferred choice should consider what impacts are more important for the specific context in which an anaerobic digestion and post-composting plant will be located. In this framework, the estimation of the emissive balance concerning different scenarios represents a useful tool for decision makers to evaluate the best option to choose.

\section{REFERENCES}

[1] Ryckebosch, E., Drouillon, M. \& Vervaeren, H., Techniques for transformation of biogas to biomethane. Biomass and Bioenergy, 35(5), pp. 1633-1645, 2011.

[2] Abdeen, F.R.H., Mel, M., Jami, M.S., Ihsan, S.I. \& Ismail, A.F., A review of chemical absorption of carbon dioxide for biogas upgrading. Chinese Journal of Chemical Engineering 24(6), pp. 693-702, 2016.

[3] Budzianowski, W.M., Wylock, C.E. \& Marciniak, P.A., Power requirements of biogas upgrading by water scrubbing and biomethane compression: Comparative analysis of various plant configurations. Energy Conversion and Management, 141, pp. 2-19, 2017.

[4] Leonzio, G., Upgrading of biogas to bio-methane with chemical absorption process: simulation and environmental impact. Journal of Cleaner Production, 131, pp. 364 375, 2016.

[5] Rotunno, P., Lanzini, A. \& Leone, P., Energy and economic analysis of a water scrubbing based biogas upgrading process for biomethane injection into the gas grid or use as transportation fuel. Renewable Energy, 102B, pp. 417-432, 2017.

[6] de Leeuw, F.A.A.M., A set of emission indicators for long-range transboundary air pollution. Environmental Science \& Policy, 5, pp. 135-145, 2002.

[7] European Environment Agency, EMEP/EEA air pollutant emission inventory guidebook, 2013.

[8] European Union Directive 2010/75/EU of the European Parliament and of the Council of 24 November 2010 on industrial emissions (integrated pollution prevention and control). Official Journal of the European Union L, 334(17), 2010.

[9] Nielsen, M., Nielsen, O.-K. \& Plejdrup, M., Danish Emission Inventories for Stationary Combustion Plants. Scientific report No. 102/2014. Danish Centre for Environment and Energy, 2014.

[10] ISPRA, Italian Greenhouse Gas Inventory 1990-2014. Technical

[11] Report No. 239/2016. Institute for Environmental Protection and Research, 2016

[12] ISPRA, Italian Emission Inventory 1990-2013. Technical report No. 223/2015. Institute for Environmental Protection and Research, 2015. 